\title{
ARTICLE \\ RIP1 promotes proliferation through G2/M checkpoint progression and mediates cisplatin-induced apoptosis and necroptosis in human ovarian cancer cells
}

Xue-lian Zheng ${ }^{1}$, Jiao-jiao Yang ${ }^{2}$, Yan-yun Wang ${ }^{1}$, Qin $\mathrm{Li}^{1}$, Ya-ping Song ${ }^{1}$, Min Su ${ }^{1}$, Jin-ke Li ${ }^{1}$, Lin Zhang ${ }^{1}$, Zhi-ping Li ${ }^{2}$, Bin Zhou ${ }^{1}$ and Yong $\operatorname{Lin}^{3}$

Receptor-interacting protein 1 (RIP1, also known as RIPK1) is not only a tumor-promoting factor in several cancers but also mediates either apoptosis or necroptosis in certain circumstances. In this study we investigated what role RIP1 plays in human ovarian cancer cells. We showed that knockout (KO) of RIP1 substantially suppressed cell proliferation, accompanied by the G2/M checkpoint arrest in two human ovarian cancer cell lines SKOV3 and A2780. On the other hand, RIP1 KO remarkably attenuated cisplatin-induced cytotoxicity, which was associated with reduction of the apoptosis markers PARP cleavage and the necroptosis marker phosphoMLKL. We found that RIP1 KO suppressed cisplatin-induced ROS accumulation in both SKOV3 and A2780 cells. ROS scavenger BHA, apoptosis inhibitor Z-VAD or necroptosis inhibitor NSA could effectively suppress cisplatin's cytotoxicity in the control cells, suggesting that ROS-mediated apoptosis and necroptosis were involved in cisplatin-induced cell death. In addition, blocking necroptosis with MLKL siRNA effectively attenuated cisplatin-induced cytotoxicity. In human ovarian cancer A2780 cell line xenograft nude mice, RIP1 KO not only significantly suppressed the tumor growth but also greatly attenuated cisplatin's anticancer activity. Our results demonstrate a dual role of RIP1 in human ovarian cancer: it acts as either a tumor-promoting factor to promote cancer cell proliferation or a tumor-suppressing factor to facilitate anticancer effects of chemotherapeutics such as cisplatin.

Keywords: RIP1; RIPK1; ovarian cancer; cisplatin; taxol; ROS; apoptosis; necroptosis; proliferation; BHA; Z-VAD; NSA

Acta Pharmacologica Sinica (2020) 41:1223-1233; https://doi.org/10.1038/s41401-019-0340-7

\section{INTRODUCTION}

Ovarian cancer is one of the main life-threatening malignancies in women worldwide. Due to its high heterogeneity and complex cell origin, the complex pathogenesis of ovarian cancer is not well elucidated [1, 2]. It is not surprising that multiple risk factors are associated with different subtypes of ovarian cancer [3]. Thus, it is important to identify factors contributing to ovarian carcinogenesis. In addition, innate and acquired resistance to commonly used chemotherapy drugs are frequently seen in ovarian cancer, which renders the worst prognosis of ovarian cancer in all gynecological malignancies [1, 2]. Thus, the identification of factors involved in this regulation and biomarkers predicting chemotherapeutic response holds important keys for improving chemotherapy efficacy to reduce ovarian cancer mortality.

Receptor-interacting protein 1 (RIP1, also known as receptorinteracting serine/threonine-protein kinase 1, RIPK1) was initially identified as an adaptor protein for the tumor necrosis factor (TNF) receptor 1 (TNFR1) family of receptors involved in nuclear factor$\kappa B(N F-\kappa B)$ activation. As NF-KB is usually anti-apoptotic, RIP1 was believed to be a mediator of cell survival. Later studies strengthened this hypothesis, as RIP1 was determined to mediate signaling pathways involved in cell survival, including the mitogen-activated protein kinases, and Akt and NF-kB, which can be activated by a variety of extracellular and intracellular stimulations and stresses [4-13]. As a hallmark of cancer cells, hyperactive cell survival pathways can be targeted for cancer chemotherapy [14]. For example, Hsp90 inhibitor-mediated destruction of RIP1 protein potently blocked NF-KB and potentiated TNF- or TNF-related apoptosis-inducing ligand-induced cancer cell death in lung cancer [15-17]. However, a pro-death role for RIP1 has also been identified: RIP1 mediates either apoptosis or necroptosis in certain circumstances [18-21]. Thus, RIP1 relays signals activated by diverse stimuli to different pathways for either cell survival or death, depending on the cellular context and types of stimulation [4, 6, 11, 22].

Recent studies have identified RIP1 as a target in therapy of human diseases, including cancer [23, 24]. RIP1 overexpression was found in glioblastoma and lung cancer, where it was suggested to be an endogenous tumor-promoting factor for these malignancies [25-27]. In lung cancer, RIP1 plays a role in counteracting the anticancer effects of chemotherapeutics, including cisplatin [28-30]. However, the role of RIP1 in

\footnotetext{
'Laboratory of Molecular and Translational Medicine, Center for Translational Medicine, Key Laboratory of Birth Defects and Related Diseases of Women and Children (Sichuan University) of Ministry of Education, Department of Obstetrics and Gynecology, West China Second University Hospital, Sichuan University, Chengdu 610041, China; ${ }^{2}$ Department

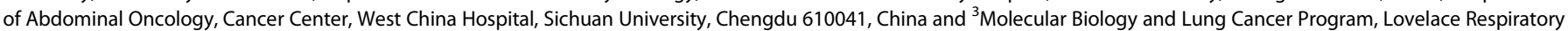
Research Institute, 2425 Ridgecrest Drive, SE, Albuquerque, NM 87108, USA

Correspondence: Bin Zhou (zb630@163.com) or Yong Lin (ylin@lrri.org)
}

Received: 9 July 2019 Accepted: 26 November 2019

Published online: 2 April 2020 
carcinogenesis and chemotherapy response in ovarian cancer has not been studied. In this report, we provide evidence, suggesting that RIP1 plays complex roles in ovarian cancer: it promotes tumor growth through increasing proliferation and counteracting the anticancer effects of chemotherapeutics such as cisplatin through mediating apoptosis and necroptosis.

\section{MATERIALS AND METHODS}

\section{Reagents}

Anti-RIP1, anti-active caspase 3 and anti-poly (ADP-ribose) polymerase (PARP) antibodies were purchased from BD Bioscience (San Diego, CA). Anti-MLKL and - $p-M L K L$ antibodies were purchased from Sigma (St. Louis, MO). Anti- $\beta$-actin and antirabbit (mouse) lgG-Hrp were purchased from Protein Tech (Chicago, IL). Anti-Ki-67 was purchased from Wuhan Boster Biological Technology, Ltd (Wuhan, Hubei, China). $N$-acetylcysteine (NAC) and butylated hydroxyanisol (BHA) were purchased from Sigma (St. Louis, MO). Z-VAD-FMK was obtained from Calbiochem (La Jolla, CA). Necrostatin-1 (Nec-1) and Necrosulfonamide (NSA) were from Abcam (Cambridge, MA). Cisplatin (cDDP) was purchased from Jiangsu Hansoh Pharma Co., Ltd (Lianyungang, Jiangsu, China). Puromycin was purchased from Sigma (St. Louis, MO). Taxol was purchased from Shanghai Haoranbio Co., Ltd (Shanghai, China).

\section{Construction of a RIP1 knockout plasmid}

A knockout (KO) plasmid targeting the human RIP1 gene was constructed using the px459 Crisper/Cas9 system (gift from Professor Qintong Li, Sichuan University) and the sequences of the inserts were as follows: h-RIP1 guide-F: 5'-CACCG AGTGCA GAACTGGACAGCGG-3'; h-RIP1 guide-R: 5'-AAAC CCGCTGTCCA GTTCTGCACTC-3'. The resulting construct, px459 RIP1 KO, was confirmed by DNA sequencing.

Cell culture and transfection

Ovarian cancer cell lines SKOV3 and A2780 from ATCC were cultured in high-glucose Dulbecco's modified Eagle's medium (DMEM) (Invitrogen) containing $400 \mathrm{mM}$ L-glutamine and 4500 $\mathrm{mg} / \mathrm{L}$ glucose $\mathrm{mL}$ penicillin, $/ \mathrm{mL}$ penicillin, $100 \mathrm{U} / \mathrm{mL}$ streptomycin, and $10 \%$ fetal bovine serum (FBS, Gibco) in a $\mathrm{CO}_{2}$ incubator at $37^{\circ} \mathrm{C}$. For stable transfection, the cells were seeded into 12-well cell culture plates and transfected with recombinant px459 RIP1 $\mathrm{KO}$ or negative control (NC) plasmids according to the instructions of a Lipofectamine 3000 Transfection Kit, and stably transfected clones were selected with puromycin $(4 \mu \mathrm{g} / \mathrm{mL})$. The clones were validated by PCR with the primers $F: 5^{\prime}-G T C T T G C C C T G A$ GGTITTCT-3' and R: 5'-CATCCCGCTCAGAACTTAGC-3', and were further confirmed by DNA sequencing and Western blotting analysis with the RIP1 antibody.

\section{Cell proliferation assays}

Cells were seeded in 96-well cell culture plates and were cultured for $12 \mathrm{~h}$ in complete DMEM containing 10\% FBS. The medium was replaced with FBS-free DMEM and cells were maintained for $24 \mathrm{~h}$ to synchronize in the $\mathrm{G} 1$ phase. To initiate cell proliferation, the FBS-free medium was replaced with complete medium. After culturing for $24,48,72$, and $96 \mathrm{~h}$, the reaction mixture from a WST$8 \mathrm{Kit}$ was added to the culture and incubated for up to $1 \mathrm{~h}$. The absorbance of the different medium mixtures was measured at $450 \mathrm{~nm}$ using a plate reader. All experiments were repeated three times and the average is shown in each figure. To examine the cell cycle distribution, the cells were cultured as in the WST-8 assay. After synchronization, the cells in the $0 \mathrm{~h}$ group were collected by trypsin digestion and the remaining cells were cultured in $10 \%$ FBS medium for $48 \mathrm{~h}$ before collection. All of the cells were treated with $75 \%$ glacial ethanol at $4{ }^{\circ} \mathrm{C}$ for $30 \mathrm{~min}$ and then they were resuspended in $20 \mu \mathrm{M}$ Draq5 from a DRAQ5 colorant Kit (KeyGEN,
China), and were incubated for $30 \mathrm{~min}$ in the dark. The cell cycle was measured by flow cytometry. All experiments were repeated three times and the average is shown in each figure.

\section{Cytotoxicity assays}

The cells were seeded in $96-$ well plates at $70-80 \%$ confluence 1 day before treatment and were treated as indicated in each figure legend. Cell death was measured based on the release of lactate dehydrogenase (LDH) using a cytotoxicity detection kit (Promega, Madison, WI, USA). Culture medium was collected from each well and transferred into a clean $96-$ well plate. The media were incubated with the reaction mixture for $30 \mathrm{~min}$ and the absorbance was measured at $490 \mathrm{~nm}$ with a plate reader. Cytotoxicity was calculated as described previously [17]. All experiments were repeated three times and the average is shown in each figure.

Detection of reactive oxygen species (ROS)

The cells cultured in 12-well plates were treated with cisplatin as shown in the figure legends. Then, 5-(and-6)-chloromethyl-2', 7'dichlorodihydro fluorescein diacetate, acetyl ester $\left(\mathrm{CM}-\mathrm{H}_{2}\right.$ DCFDA, $5 \mu \mathrm{M})$ was added to the cell culture $30 \mathrm{~min}$ before cells were collected and ROS was detected by flow cytometry with a BD FACSCelesta flow cytometer (BD Biosciences, Franklin Lakes, NJ, USA).

Western blotting analysis

Cells were collected by trypsin digestion and cell lysates were prepared by putting cells in RIPA buffer supplemented with the protease inhibitor phenylmethanesulfonyl fluoride. Total protein concentration was measured with a BCA protein assay kit (Thermo, USA). Equal protein amounts of the samples were resolved on SDS-polyacrylamide gels by electrophoresis and transferred to polyvinylidene difluoride membranes with a Trans-Blot ${ }^{\circledR}$ Turbo $^{\text {TM }}$ Transfer System (Bio-Rad). The membranes were blocked with a blocking buffer containing $5 \%$ bovine serum albumin before incubating with primary antibodies overnight. The membranes were then incubated with horseradish peroxidaseconjugated secondary antibodies for $1 \mathrm{~h}$ and the proteins of interest were visualized by enhanced chemiluminescence (Millipore, Billerica, MA, USA). The intensity of each band was quantified by ImageJ software.

\section{Apoptosis assays}

Apoptosis was detected by using a PE Annexin V Apoptosis Detection Kit with 7-AAD (Biolegend, USA). The cells were seeded in six-well plates and cultured in DMEM containing 10\% FBS overnight, treated with cisplatin as indicated in figure legends, and then collected by EDTA-free trypsin digestion. The cells were double stained with PE Annexin V and 7-AAD, and apoptosis was measured and analyzed by flow cytometry (BD Bioscience, Franklin Lakes, NJ). Early apoptosis was defined by PE Annexin V/7-AAD staining (Q4) and late apoptosis was defined by PE Annexin V/7-AAD staining (Q2). All experiments were repeated three times and a representive set is shown in each Fig. 4.

\section{RNA interference}

To knock down MLKL expression, cells were transfected with an MLKL small interfering RNA (siRNA) with the Lipofectamine 3000 Transfection Kit using siRNA transfection reagent. A negative control siRNA was transfected as an NC. The knockdown efficacy was determined by Western blotting. To evaluate the effect of MLKL knockdown on cisplatin sensitivity, siRNA-transfected cells were treated with cisplatin for another $72 \mathrm{~h}$ and cell death was measured with an LDH release assay. The siRNA targeting sequences were as follows: MLKL-1: 5'-GAAGCAUAUUAUCACC CUUTT-3', MLKL-2: sense: 5'-GCAAUAGAUCCAAUAUCUGTT-3', and NC: 5'-UUC UCC GAA CGU GUC ACG UTT-3'. 
a

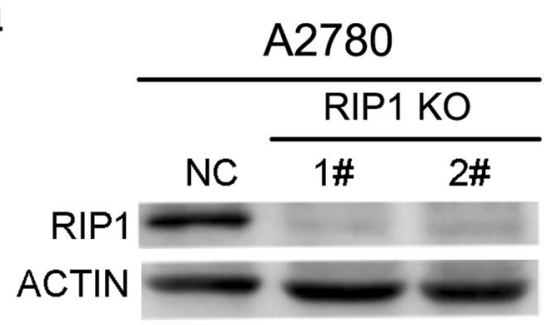

C

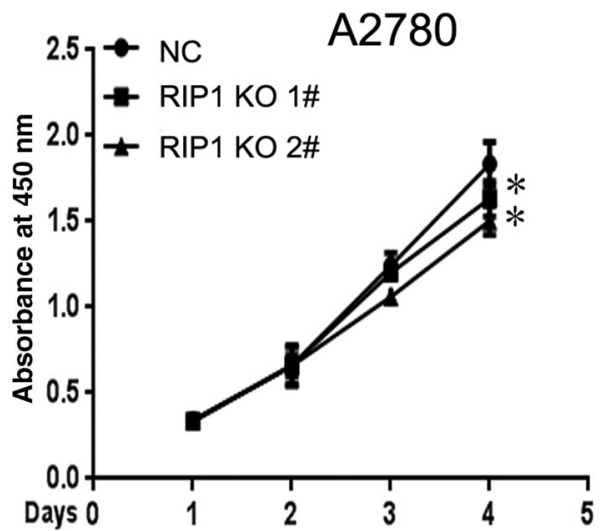

b

SKOV3

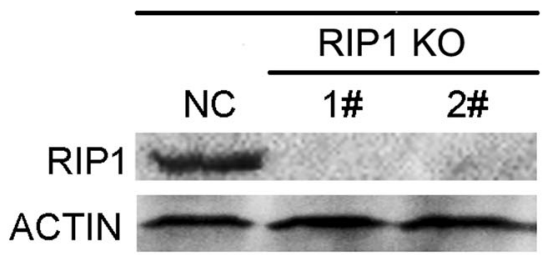

d

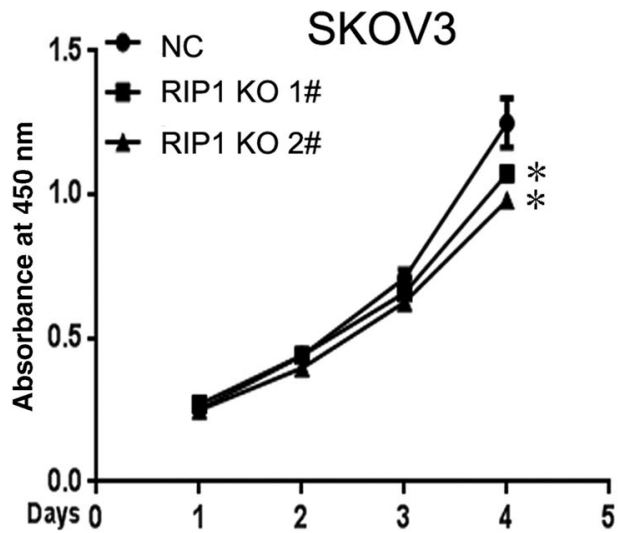

e

\section{NC}

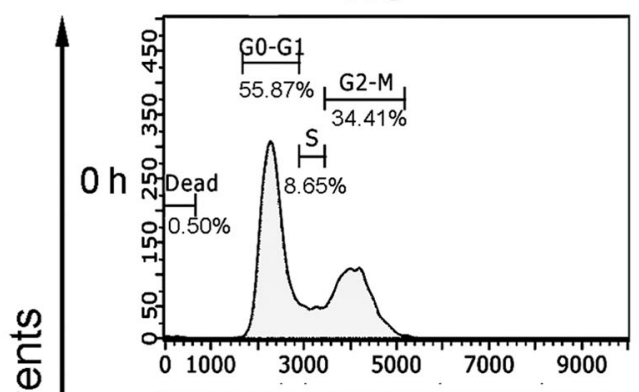

एᄂ

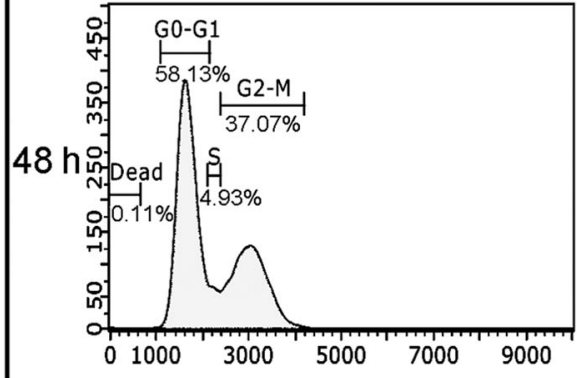

RIP1 KO 1\#
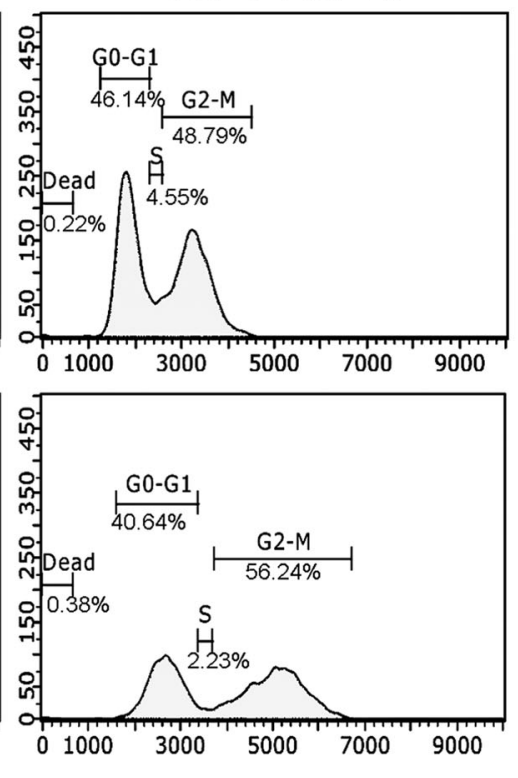

DRAQ5 Staining

Fig. 1 RIP1 knockout suppressed ovarian cancer cell proliferation a, b Stable RIP1 knockout in SKOV3 and A2780 cells was confirmed by Western blotting. NC, negative control transfected cells. $\beta$-Actin was detected as an input control. c, $\mathbf{d}$ Cell proliferation assay. Cells were cultured for the indicated time points and relative cell proliferation was measured by WST assay. Data shown are the mean \pm SD. ${ }^{* * P}<0.05$. e Cell cycle distribution was measured by flow cytometry following DRAQ5 staining.

Xenograft tumor growth and therapy assays

All of the procedures involving animal use and care were approved by the Institutional Animal Care and Use Committee of Sichuan University. Balb/c Nude mice (5-6 weeks old, female) were purchased from a corporation for experimental animals (Gempharmatech. Co., Ltd, Jiangsu, China). Cells $\left(6 \times 10^{6}\right.$ cells) were injected subcutaneously into the flanks of the mice. After palpable tumors had developed, the animals in each group were randomly divided into two subgroups for treatment with either phosphate-buffered saline (PBS) (control) or cisplatin $(4.5 \mathrm{mg} / \mathrm{kg}$ body weight, intraperitoneally, twice a week). The body weight and tumor size were measured twice a week. Tumor volume was calculated using the following formula: tumor volume $=$ (length $\times$ width $\left.^{2}\right) / 2$. At the end of the experiment, the animals were killed and excised tumors were measured and weighed. The antitumor effect for each group was expressed as the tumor inhibition rate: 
[(mean tumor weight of PBS group - tumor weights of the cisplatin-treated group)/mean tumor weight of PBS group] $\times$ $100 \%$.

Immunohistochemistry

Paraffin-embedded sections of tumor tissues were treated with 3\% $\mathrm{H}_{2} \mathrm{O}_{2}$ for 10 min at room temperature after conventional dewaxing to inactivate endogenous peroxidase. Goat serum was used to block samples for $20 \mathrm{~min}$ at room temperature after antigen retrieval with $0.01 \mathrm{M}$ sodium citrate buffer $(\mathrm{pH} \mathrm{6.0)}$. The sections were incubated with primary antibodies (RIP1 and Ki-67 concentrations were both $1: 100$ ) overnight at $4{ }^{\circ} \mathrm{C}$ and then they were incubated with the biotin-coupled secondary antibody (GTVision ${ }^{T M}$ III Detection System/Mo\&Rb, Shanghai Gene Technology Co., Ltd) for $30 \mathrm{~min}$ at $37^{\circ} \mathrm{C}$. Hematoxylin was used to counterstain the slides. The images were observed under a microscope.

Detection of apoptosis and necroptosis in tumors

Apoptosis in tumor tissues was detected by terminal deoxynucleotidyl transferase dUTP nick-end labeling (TUNEL) assays with an In Situ Cell Death Detection Kit (Roche Diagnostics, Mannheim, Germany) according to the manufacturer's instructions. Briefly, paraffin-embedded tissue sections were deparaffinized, treated with $0.01 \mathrm{M}$ Tris $/ \mathrm{HCl}$ protease $\mathrm{K}\left(20 \mu \mathrm{g} / \mathrm{mL}\right.$ at $\left.37^{\circ} \mathrm{C}\right)$ for $15 \mathrm{~min}$, and then incubated with the terminal deoxynucleotidyl transferase labeling reaction mixture for $60 \mathrm{~min}$ at $37^{\circ} \mathrm{C}$. The primary antibody (anti-Caspase-3, 1:100) was incubated with the cells overnight at $4{ }^{\circ} \mathrm{C}$ and the fluorescently labeled secondary antibody was incubated with the cells for $1 \mathrm{~h}$ at room temperature after washing with PBS. The nuclei were stained with 4',6-diamidino-2phenylindole and the pictures were taken by confocal microscopy. As apoptotic cells involve caspase activation and DNA damage while necroptosis results in caspase-independent DNA damage [31-33], cells positive for both TUNEL and active Caspase 3 were regarded as apoptotic and those only positive for TUNEL staining were regarded as necroptotic.

Statistical analysis

Statistical significance was examined by Student's paired-samples $T$-test by using SPSS statistics software. $P<0.05$ was used to identify significance.

\section{RESULTS}

RIP1 knockout suppresses proliferation in ovarian cancer cells To investigate the role of RIP1 in ovarian cancer, we established stable RIP1 expression KO with CRISPR/Cas9 in two human ovarian cancer cell lines SKOV3 and A2780. Individual RIP1 KO clones were validated by Western blotting (Fig. 1a, b). Compared with negative control (NC)-transfected control cells, the proliferation of the RIP1 $\mathrm{KO}$ clones was substantially reduced (Fig. 1c, d), suggesting that RIP1 is required for proliferation of ovarian cells. To investigate the underlying mechanism of this effect of RIP1, the cell cycle distribution of the KO cells was examined by staining with DRAQ5 and subjecting them to flow cytometry analysis. The RIP1 KO clones consistently had much higher distribution rates in the G2/M phase than in the NC cells (Fig. 1e), suggesting that knocking out RIP1 resulted in cell cycle arrest at the G2/M checkpoint. These results suggest that RIP1 potentiates ovarian cancer cell proliferation by promoting the G2/M transition in the cell proliferation cycle.

RIP1 KO attenuates cytotoxicity induced by cisplatin and Taxol in ovarian cells

Correlated to the pivotal role of RIP1 in cell survival signaling, RIP1 ablation sensitized lung cancer cells to chemotherapeutics [28-30]. Thus, we examined whether RIP1 plays a similar role in ovarian cancer. Surprisingly, RIP1 KO strongly suppressed cisplatin-induced cell death in both SKOV3 and A2780 cells (Fig. 2a, b). A similar effect a

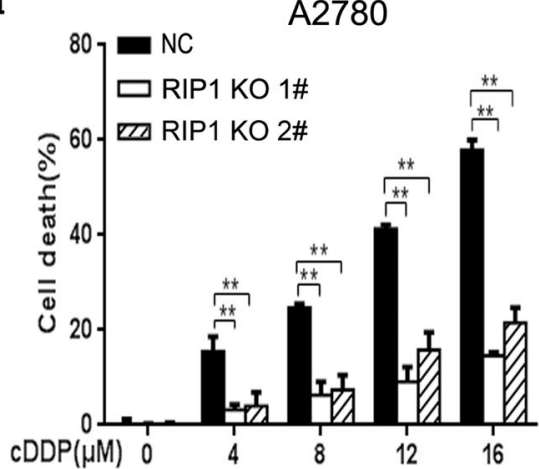

b

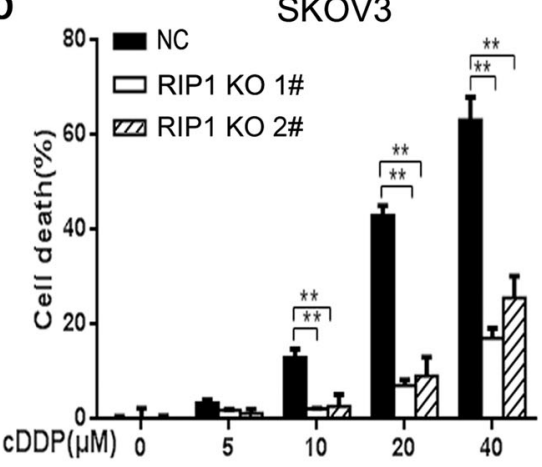

C

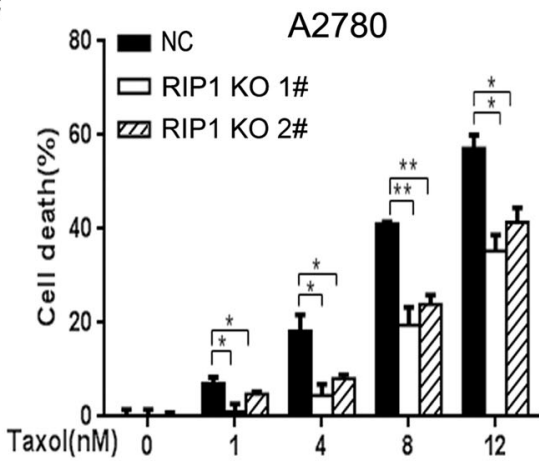

d

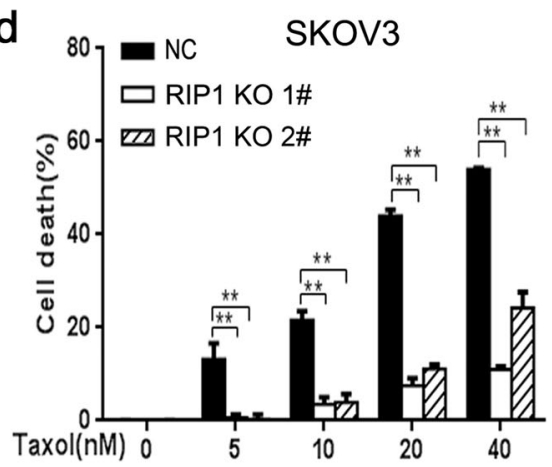

Fig. 2 RIP1 knockout attenuated cytotoxicity induced by cisplatin and Taxol in ovarian cancer cells. a, b Stable RIP1 knockout and control (NC, negative control transfected) cells were treated with different concentrations of cisplatin as indicated for $72 \mathrm{~h}$. Cell death was measured by LDH release assay. c, d Stable RIP1 knockout and control (NC, negative shRNA transfected) cells were treated with Taxol for $48 \mathrm{~h}$. Cell death was measured by LDH release assay. Data shown are the mean \pm SD. ${ }^{* *} P<0.01,{ }^{*} P<0.05$. 
a

NC

RIP1 KO 1\#

RIP1 KO 2\#

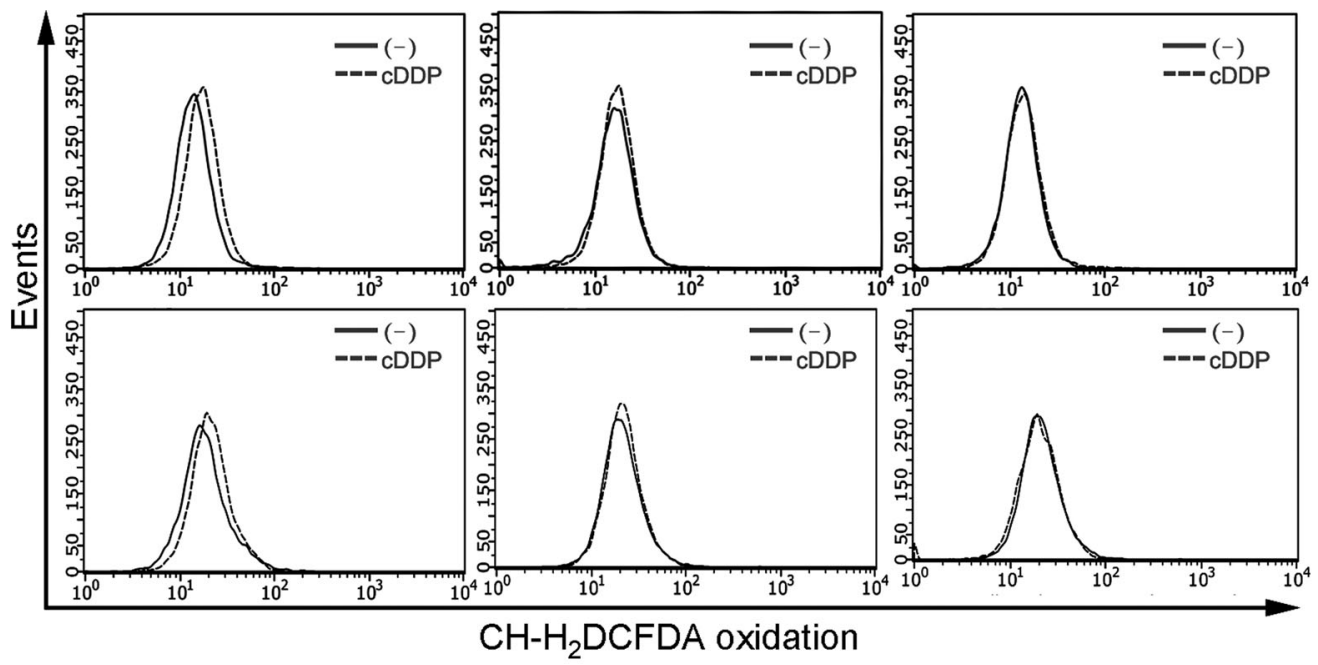

A2780

SKOV3

b

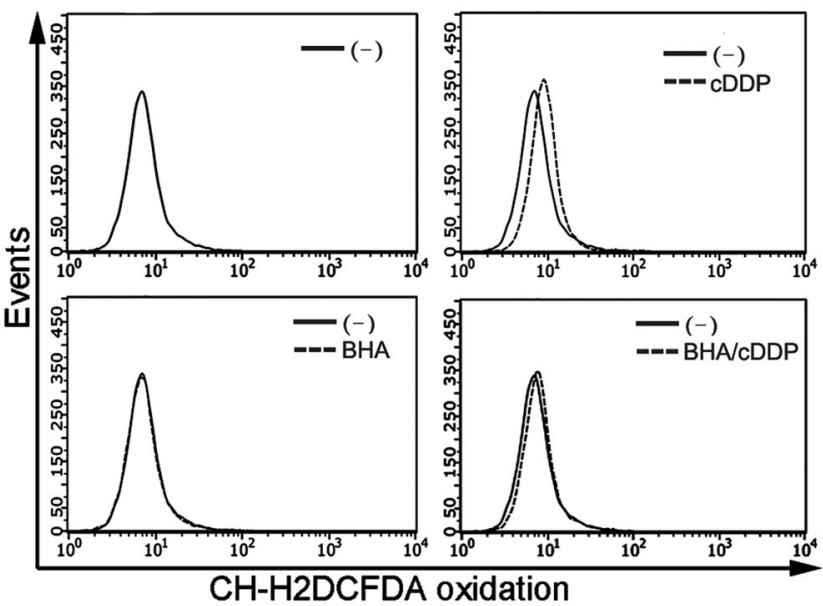

d

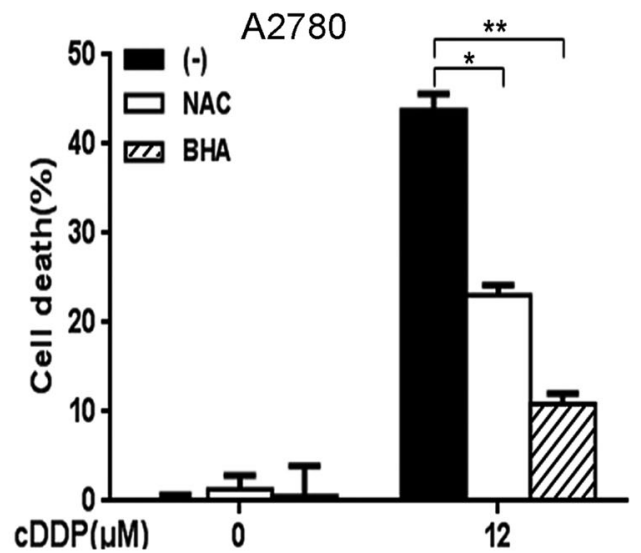

C

SKOV3

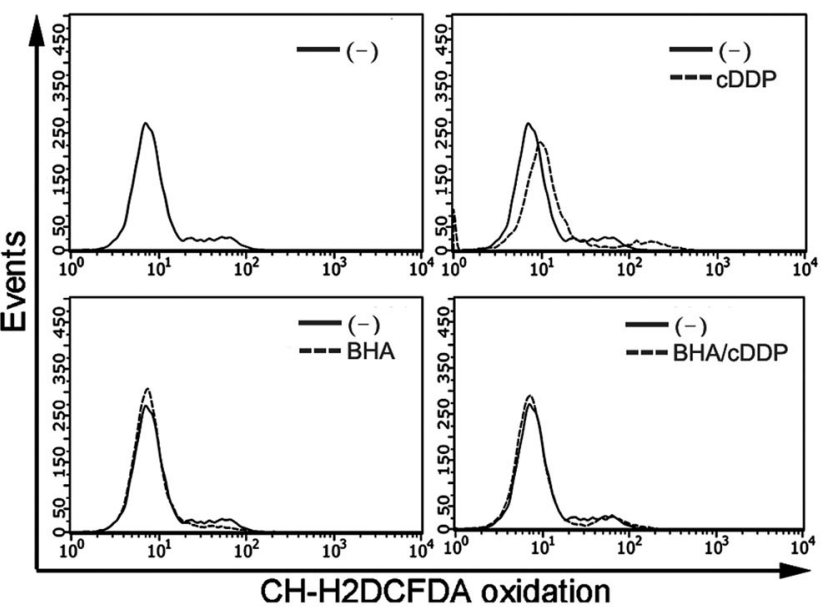

e

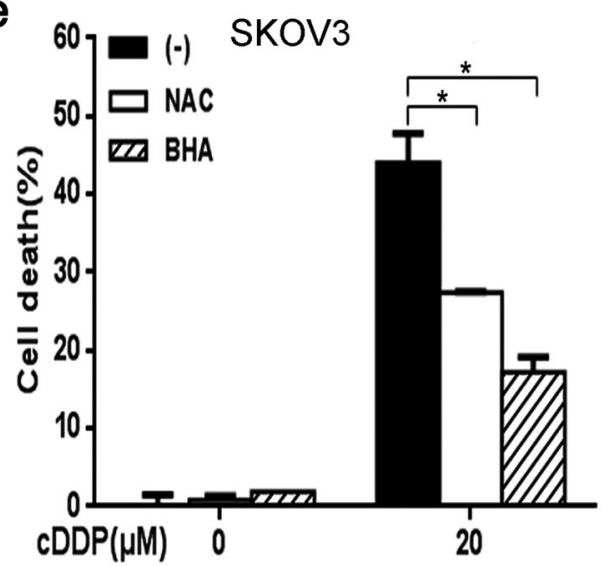

Fig. 3 RIP1 knockout suppressed cisplatin-induced intracellular ROS accumulation, which contributed to cisplatin-induced cytotoxicity. a Cells were treated with cisplatin (A2780: $12 \mu \mathrm{M}$ and SKOV3: $20 \mu \mathrm{M}$ ) for $24 \mathrm{~h}$ and incubated with CM- $\mathrm{H}_{2}$ DCFDA (5 $\left.\mu \mathrm{M}\right)$ for 30 min before being collected for ROS detection by flow cytometry. b, c Cells were pretreated with ROS scavenger BHA (100 $\mu \mathrm{M})$ for $1 \mathrm{~h}$. Then, cells were treated with cisplatin (A2780: $12 \mu \mathrm{M}$ and SKOV3: $20 \mu \mathrm{M}$ ) for $24 \mathrm{~h}$ and incubated with CM-H 2 DCFDA (5 $\mu \mathrm{M}$ ) for 30 min before being collected for ROS detection by flow cytometry. d, e Cells were pretreated with NAC $(1 \mathrm{mM})$ or BHA $(100 \mu \mathrm{M})$ for $1 \mathrm{~h}$ followed by cisplatin (A2780: $12 \mu \mathrm{M}$ and SKOV3: $20 \mu \mathrm{M}$ ) treatment for $72 \mathrm{~h}$. Cell death was detected by LDH release assay. Data shown are the mean \pm SD. ${ }^{* *} P<0.01,{ }^{*} P<0.05$. 
a $\quad \mathrm{A} 2780$

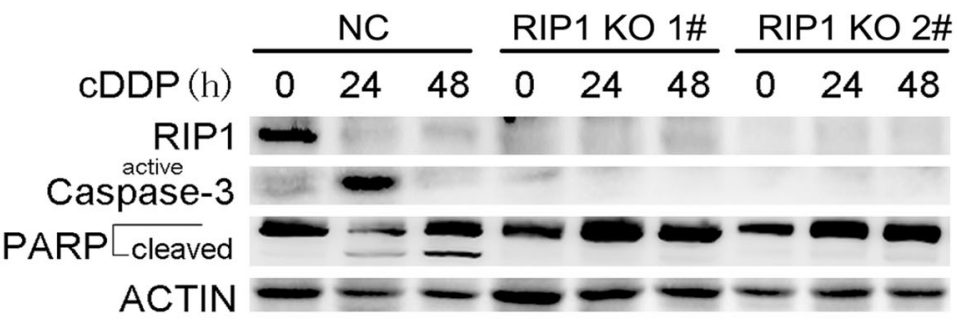

b

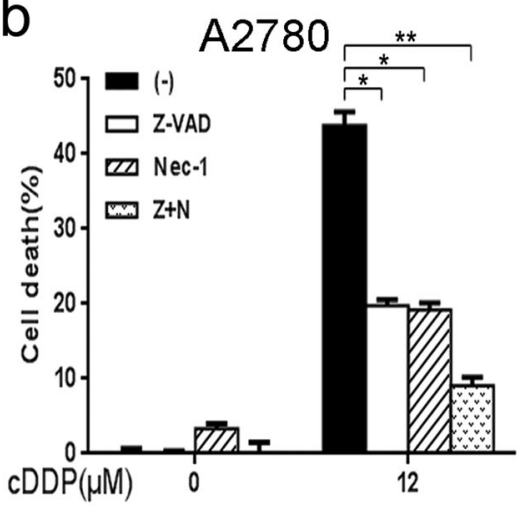

C

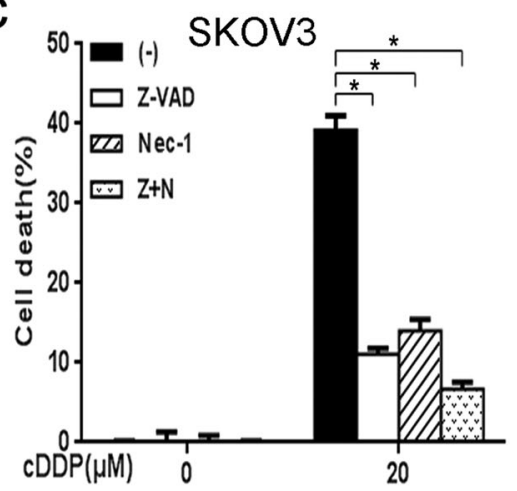

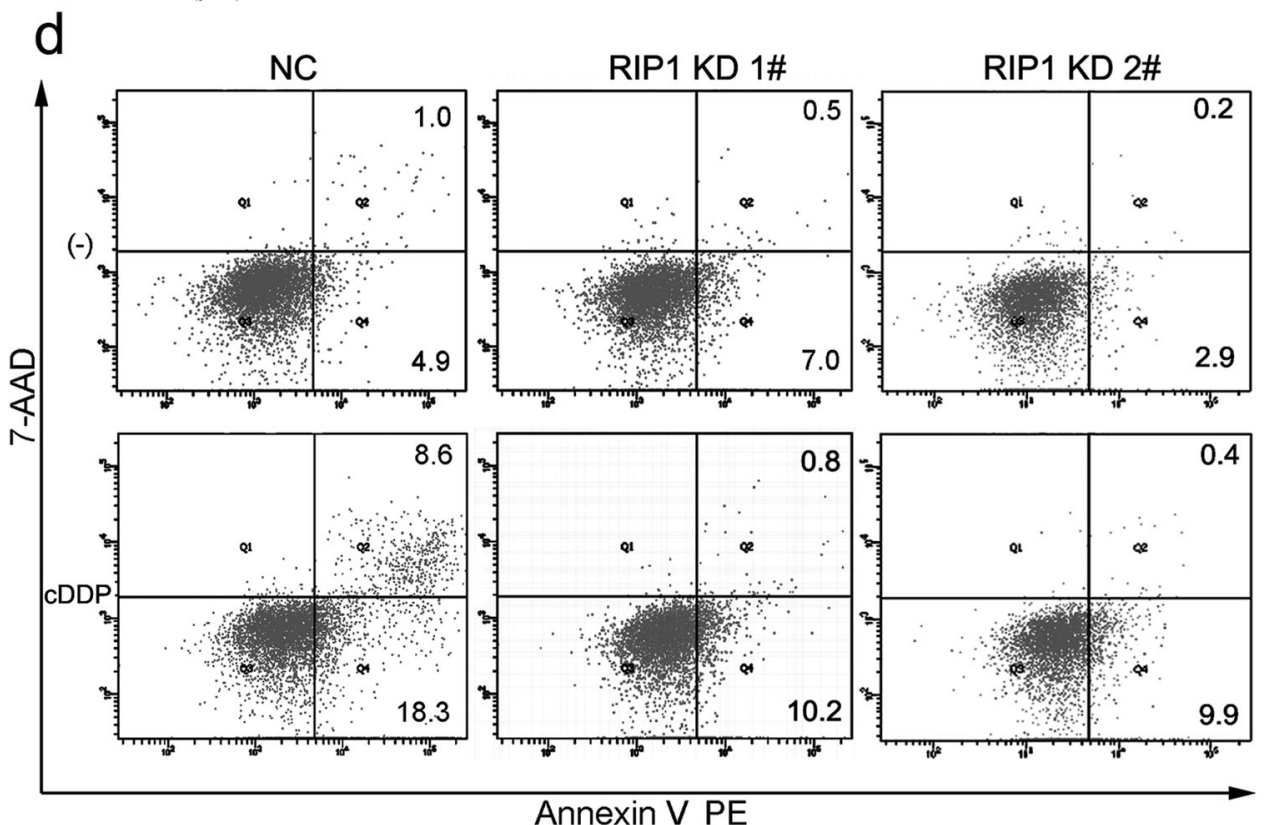

Fig. 4 RIP1 knockout suppressed cisplatin-induced apoptosis. a Stable RIP1 KO and NC A2780 cell clones were treated with cisplatin (12 $\mu$ M) for 0,24 , and $48 \mathrm{~h}$. Active caspase 3 and PARP were detected by Western blotting. $\beta$-Actin was detected as an input control. b, $\mathbf{c}$ NC cells were pretreated with Z-VAD-fmk $(20 \mu \mathrm{M})$, necrostatin-1 $(30 \mu \mathrm{M})$, or both $(\mathrm{N}+\mathrm{Z})$ for $1 \mathrm{~h}$, or remained untreated before exposure to cisplatin $(\mathrm{A} 2780$ : $12 \mu \mathrm{M}$ and SKOV3: $20 \mu \mathrm{M}$ ) for $72 \mathrm{~h}$. Cell death was detected by LDH release assay. Data shown are the mean \pm SD. ${ }^{*} P<0.05$. d The A2780 cells were treated with cisplatin $(12 \mu \mathrm{M})$ for $48 \mathrm{~h}$ or were left untreated. Apoptosis was measured by flow cytometry following staining with annexin V and 7-AAD.

was observed when the cells were treated with Taxol (Fig. 2c, d). Consistently, there was a significant increase in cisplatin-induced cytotoxicity in the RIP1 overexpression cells (Supplementary Fig. S1). These unexpected results strongly suggest that RIP1 is required for the chemotherapy response in ovarian cancer, which is different from what is observed in other cancers [25-27].

RIP1 KO suppresses cisplatin-induced ROS accumulation Previous reports showed that RIP1 attenuates the chemotherapeutic response of lung cancer cells through mitigating cellular ROS accumulation $[28,30]$. Thus, we examined whether RIP1 KO influences ROS induction by cisplatin. As expected, cisplatin treatment caused cellular ROS accumulation in the NC cells (Fig. 3a). However, although the basal ROS level was not changed, the cisplatin-induced ROS was almost completely suppressed by RIP1 KO in both SKOV3 and A2780 cells (Fig. 3a). Consistently, RIP1 overexpression slightly promoted cisplatin-induced ROS levels (Supplementary Fig. S1e). The role of ROS in cisplatin-induced cytotoxicity was confirmed with ROS scavengers BHA and NAC, which effectively suppressed cisplatin's cytotoxicity in the NC cells due to the effective removal of cellular ROS (Fig. 3b-e). These results suggest that RIP1 in ovarian cancer cells plays an opposite 
a

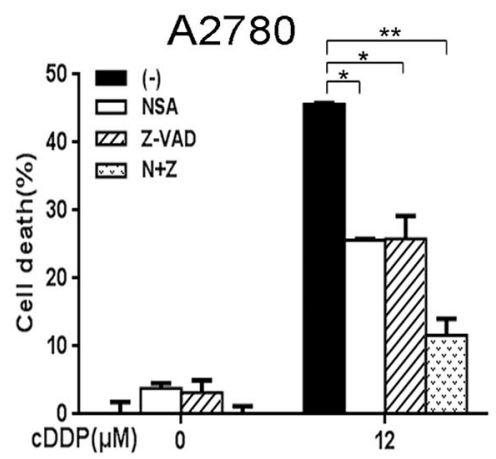

C

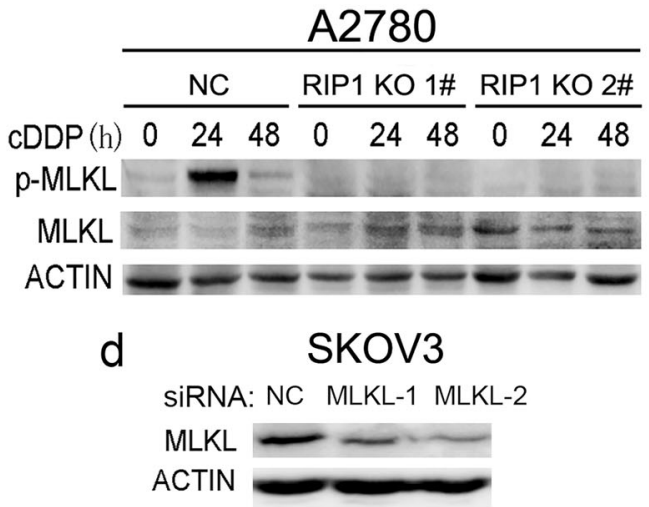

b

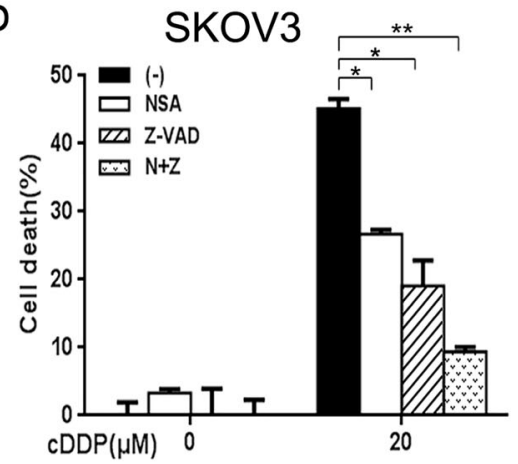

e

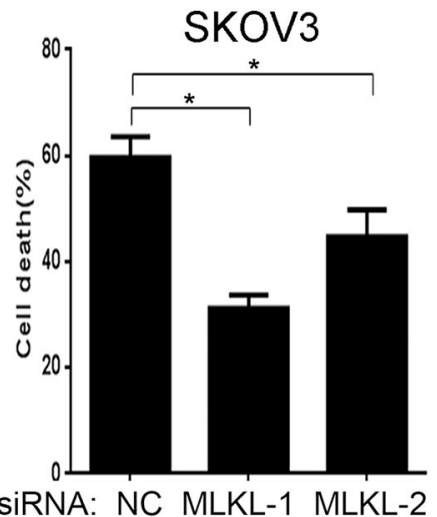

Fig. 5 RIP1 knockout suppressed cisplatin-induced necroptosis. a, b NC cells were pretreated with Z-VAD-fmk (20 $\mu$ M), NSA ( $2 \mu \mathrm{M})$ or both $(\mathrm{N}+\mathrm{Z})$ for $1 \mathrm{~h}$ or remained untreated and then were exposed to cisplatin (A2780: $12 \mu \mathrm{M}$ and SKOV3: $20 \mu \mathrm{M})$ for $72 \mathrm{~h}$. Cell death was detected by LDH-releasing assay. The data shown are the mean \pm SD. ${ }^{*} P<0.05,{ }^{*} P<0.01$. c Stable RIP1 KO and NC A2780 cell clones were treated with cisplatin $(12 \mu \mathrm{M})$ for 0,24 , and $48 \mathrm{~h}$. The indicated proteins were detected by Western blot. $\beta$-Actin was detected as an input control. $\mathbf{d}$ SKOV3 cells were transfected with MLKL siRNA or negative control siRNA, and MLKL knockdown was confirmed by Western blotting. e The cells were treated with cisplatin $(20 \mu \mathrm{M})$ for $72 \mathrm{~h}$. Cell death was detected by LDH release assay. Data shown are the mean \pm SD. ${ }^{*} P<0.05$.

role in ROS regulation to the role it plays in lung cancer, where RIP1 suppresses cisplatin-induced ROS [28, 30], which explains the opposite roles of RIP1 in cisplatin-induced cytotoxicity in different cancers.

RIP1 mediates cisplatin-induced apoptosis

It is well known that cisplatin induces apoptotic cell death in various cancer cells, and that excess cellular ROS can lead to apoptosis. Therefore, we examined whether RIP1 mediates cisplatin-induced apoptosis in ovarian cancer cells. Indeed, cisplatin-induced caspase 3 activation and PARP cleavage, hallmarks of apoptosis activation, were effectively suppressed in RIP KO cells (Fig. 4a). Notably, cisplatin suppressed RIP1 expression at 24 and $48 \mathrm{~h}$, late time points when signaling to apoptosis was completed, which is consistent with the fact that RIP1 can be cleaved or degraded to terminate its signaling [4, 34]. In addition, the pan caspase inhibitor Z-VAD and RIP1 kinase inhibitor necrostatin-1 effectively suppressed cisplatin-induced cytotoxicity (Fig. 4b, c). Furthermore, suppressed cisplatin-induced apoptosis in RIP1 KO cells was confirmed by annexin V staining (Fig. 4d).

RIP1 contributes to cisplatin-induced necroptosis

The combination of Z-VAD and necrostatin-1 additively suppressed cisplatin-induced cell death (Fig. 4b, c), suggesting that a mechanism in addition to apoptosis was mediated by RIP1 for cisplatin's cytotoxicity. As RIP1 is able to mediate necroptosis in certain circumstances, we then examined whether mediation of necroptosis by RIP1 is also involved in cisplatin-induced cytotoxicity in ovarian cancer cells. Similar to Z-VAD, the necroptosis inhibitor NSA also effectively suppressed cisplatin-induced cell death in both SKOV 3 and $A 2780$ cells, and the combination of Z-VAD and NSA resulted in further suppression of cytotoxicity (Fig. 5a, b). Then, the phosphorylation of MLKL, a hallmark of necroptosis activation, was examined by Western blotting. A strong phosphorylation of MLKL was detected in the NC cells but not in the RIP1 KO cells at $24 \mathrm{~h}$ post cisplatin exposure (Fig. $5 \mathrm{c}$ ), which was correlated with the timing of necroptosis activation. When MLKL was knocked down (Fig. 5d), cisplatin-induced cell death was reduced (Fig. 5e), confirming that cisplatin is able to induce necroptosis in ovarian cancer cells. Altogether, these results suggest that RIP1 mediates cisplatin-induced necroptosis in ovarian cancer cells.

RIP1 KO attenuates tumor growth in nude mice

A mouse xenograft tumor model was used to examine the role of RIP1 in ovarian cancer growth in vivo. The NC and RIP1 KO cells were injected subcutaneously into nude mice to allow the development of xenograft tumors and subsequent tumor growth was measured. The tumors derived from RIP1 KO cells grew significantly slower and were smaller than those from the NC cells (Fig. 6a, c-e), which is consistent with the attenuated proliferation in RIP1 KO cells seen in vitro (Fig. 1c-e). Supportive of the role of RIP1 in tumor growth, the cell proliferation marker Ki-67 was significantly reduced in the tumors derived from RIP1 KO cells compared with what was seen in tumors derived from the NC cells (Fig. 6f).

RIP1 KO attenuates cisplatin's anticancer activity in nude mice The role of RIP1 in response to the antitumor effect of cisplatin was examined in a xenograft tumor therapy model. As expected, cisplatin therapy strongly suppressed tumors derived from NC 
a

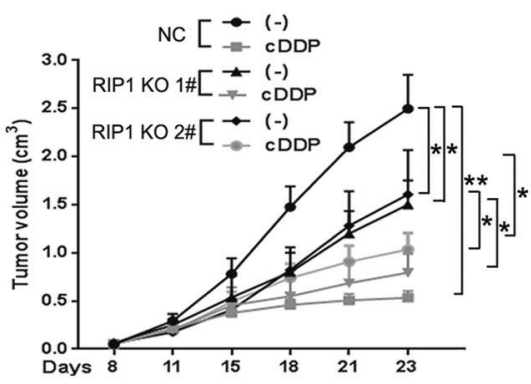

C

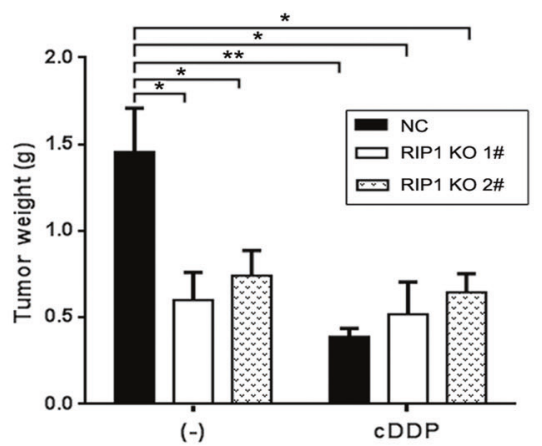

b

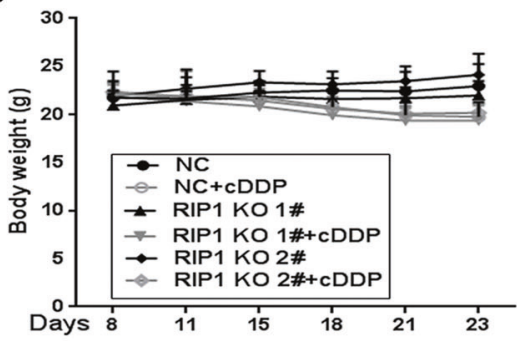

d

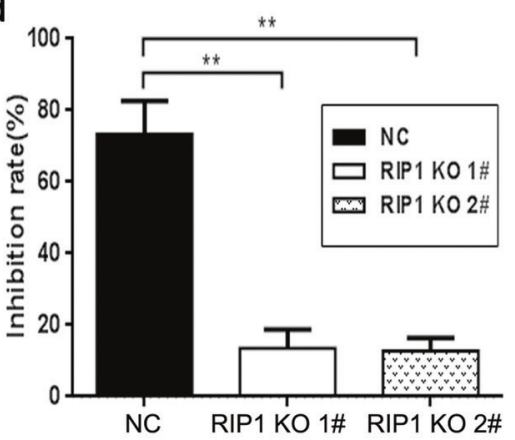

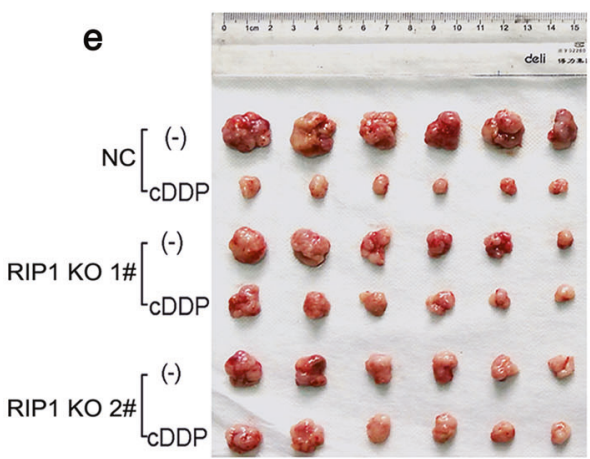

f

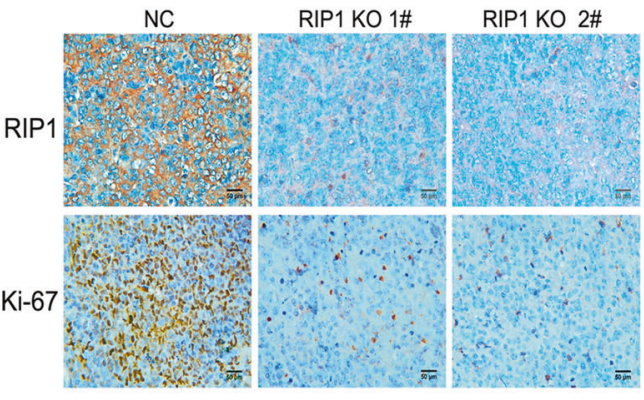

Fig. 6 RIP1 knockout attenuated xenograft tumor growth and cisplatin's anticancer activity in nude mice. a Athymic nude mice were inoculated subcutaneously in the flanks with A2780 NC cells or RIP1 KO cells to assess the development of xenograft tumors. The mice were then treated with cisplatin $(4.5 \mathrm{mg} / \mathrm{kg}$ of body weight). The volume of tumors was measured and the mean tumor size of each group is shown. Error bars, SD. ${ }^{*} P<0.05,{ }^{*} P<0.01$. b Average of mouse body weight. c Tumor weight. $\mathbf{d}$ Inhibition rate induced by cDDP. e Xenograft tumors excised from the mice. $f$ The cell proliferation marker Ki-67 detected by IHC.

cells. In contrast, the tumor-suppressing effect of cisplatin in tumors derived from RIP1 KO cells was subtle (Fig. 6a, c, d). These results confirmed the role of RIP1 in potentiating tumor growth and mediating cisplatin's anticancer activity in vivo. In addition, cisplatin therapy induced both apoptosis (as indicated from positive staining for both TUNEL and active Caspase 3) and necroptosis (cells positive for TUNEL only) (Fig. 7). Importantly, RIP1 KO significantly reduced the number of both cisplatininduced apoptotic and necrotic cells (Fig. 7a, b), suggesting that RIP1 mediated both apoptosis and necroptosis for cisplatin's anticancer activity in vivo.

\section{DISCUSSION}

In this report, we provide data suggesting that RIP1 plays a dual role in ovarian cancer: as a tumor-promoting factor to maintain cancer cell proliferation and as a tumor-suppressing factor to facilitate the anticancer activity of chemotherapeutics such as cisplatin. The results show that RIP1 KO substantially suppressed cell proliferation through arrest at the G2/M checkpoint. RIP1 KO remarkably attenuated cisplatin-induced cytotoxicity, which was associated with suppression of apoptosis and necroptosis. The cellular role of RIP1 in regulating cisplatin-induced cell death is likely due to the mediation of ROS production. Thus, our results highlight the complex properties of RIP1 in ovarian cancer, and RIP1 expression may be used as a biomarker for predicting platinum-based chemotherapy response.

As a cell survival factor, RIP1 contributes to cell proliferation [4]. The mediation of signals related to survival, such as NF-KB and Akt, is generally assumed to be the mechanism by which RIP1 contributes to cell survival and proliferation $[35,36]$. RIP1 also maintains mitochondrial oxidative phosphorylation and a proper level of glycolysis to support cell proliferation in lung cancer cells [37]. Thus, the role of RIP1 in cancer cell proliferation appears to be complex. In this report, we found that RIP1 KO clearly suppressed proliferation in vitro and tumor growth in vivo. The proliferation suppression was due to cell cycle arrest at the G2/M checkpoint. However, the defined mechanism underlying this function of RIP1 needs future study.

RIP1 was initially found to mediate TNFa-induced ROS accumulation and necroptosis in mouse embryonic fibroblast cells [20]. However, later studies found that RIP1 suppresses and does not promote ROS in lung cancer cells exposed to chemotherapeutic drugs such as cisplatin and adriamycin. By 


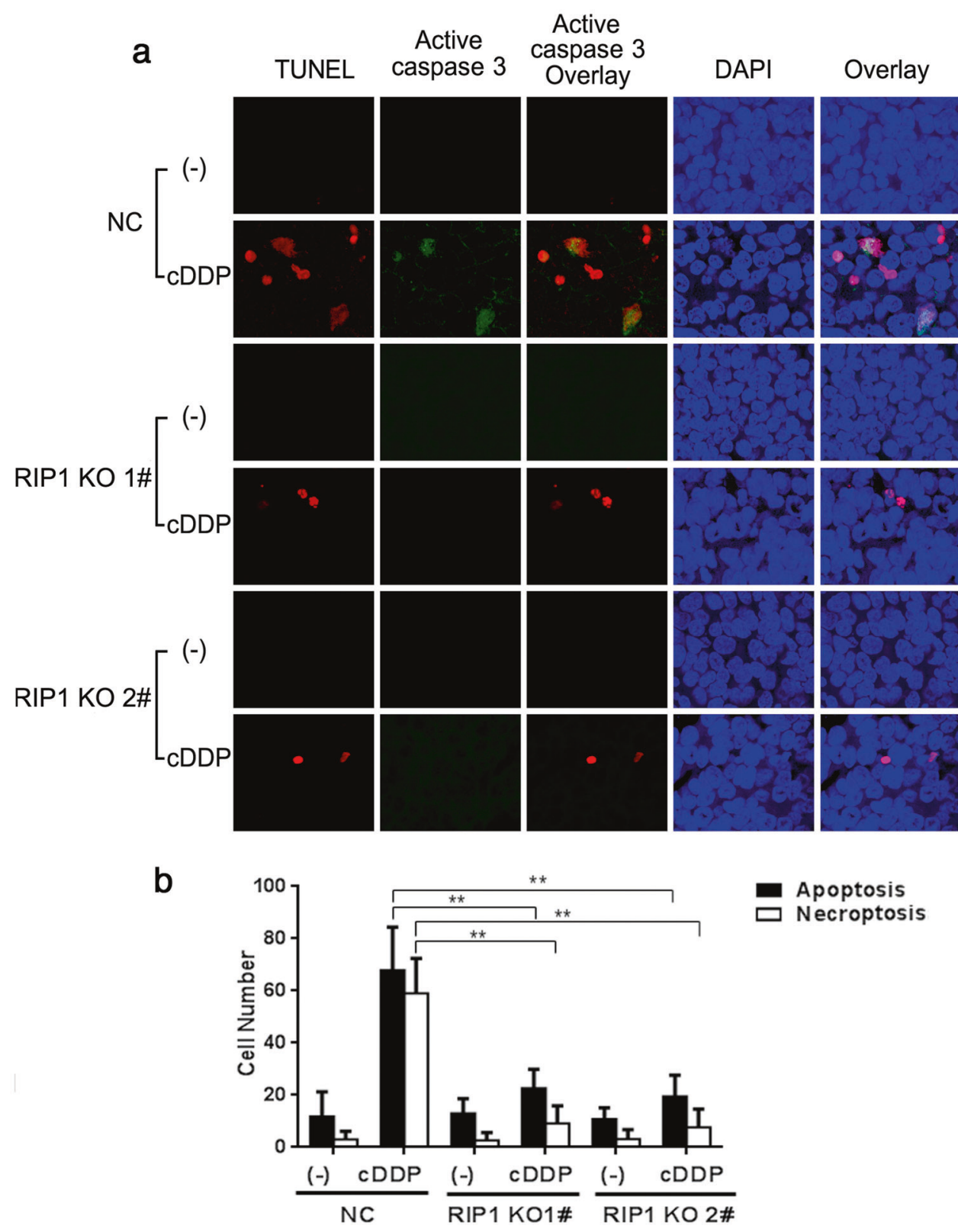

Fig. 7 RIP1 knockout attenuated cisplatin-induced apoptotic and necrotic cell death in xenograft tumors in nude mice. a The tumor tissues from the experiment shown in Fig. 6 were analyzed for apoptosis and necroptosis as described in the Materials and Methods. Cisplatin therapy induced both apoptosis [shown as positive for both TUNEL (red) and active Caspase 3 (green)] and necroptosis (cells positive for TUNEL only) in the tumors. In the RIP1 KO tumors, both the numbers of cisplatin-induced apoptotic and necrotic cells were significantly reduced compared with what was observed in the NC tumors. b Quantification of apoptotic and necroptotic cell numbers. More than 300 cells were counted and the results are shown as the mean \pm SD. Columns represent the mean in each group and bars represent SD. ${ }^{* *} P<0.01$.

suppressing ROS accumulation, RIP1 attenuates anticancer activity in lung cancer cells [28-30]. In this report, we found that RIP1 is required for cisplatin-induced and ROS-mediated cytotoxicity, which is clearly different from the results from lung cancer cells. Thus, it is likely that the role of RIP1 in the regulation of ROS and chemotherapy response is cell type- or context-specific. Indeed, RIP1-dependent ROS production was reported to contribute to artesunate-induced cell death in renal carcinoma cells [38]. How RIP1 mediates contradictory cellular signaling in different cells is still elusive. RIP1 modifications, such as phosphorylation, ubiquitination and cleavage, may be involved $[34,39]$. Future studies on the expression and function of RIP1-modulating factors in cancers in which RIP1 exerts distinct functions may uncover some pieces of the puzzle.
As a cytotoxic anticancer therapeutic agent, it is well known that cisplatin induces apoptosis. We found that cisplatin's cytotoxicity is partially apoptotic, as it was shown to activate caspases and could be partly suppressed by the apoptosis inhibitor z-VAD. The apoptotic effect was effectively suppressed by RIP1 KO or the RIP1 kinase inhibitor Nec-1, suggesting that RIP1 mediates cisplatin-induced apoptosis. This is consistent with the idea that under certain circumstances, RIP1 mediates apoptosis depending on its kinase activity [18].

Necroptosis was initially defined as death receptor-initiated and RIP1/RIP3-mediated nonapoptotic cell death [40, 41]. The formation of the necrosome signaling complex is key for mediating necrotic cell death mediated by death receptors $[42,43]$. Later, intrinsic stress-induced necroptosis was discovered, 
and pharmacological agents induced necroptosis through necrosome formation $[42,44]$. Recent studies suggest that cisplatin can also trigger necroptosis in mouse fibroblast L929 cells [45]. In this study, we determined that cisplatin is able to induce necroptosis, which can be blocked by either the necroptosis inhibitor NSA or the knockdown of MLKL. Thus, cisplatin cytotoxicity in ovarian cells involves both apoptosis and necroptosis, and in which RIP1 plays a pivotal role.

In summary, our results suggest that RIP1 promotes ovarian cancer cell proliferation through G2/M checkpoint progression and facilitates anticancer effects of chemotherapeutics such as cisplatin and Taxol. Further studies are warranted with animal models to determine if RIP1 is involved in ovarian carcinogenesis and with clinical studies to determine if RIP1 expression could be a biomarker for predicting responses to chemotherapy.

\section{ACKNOWLEDGEMENTS}

This work was supported in part by grants from the National Natural Science Foundation of China (Numbers 81172494 and 81670346), the R\&D Program for International S\&T Cooperation and the Exchanges of Sichuan province (Number 2018H 0014), and NCI/NIH (1R21CA193633).

\section{AUTHOR CONTRIBUTIONS}

$B Z$ and $Y L$ designed the research and wrote the manuscript. $X L Z, J J Y, Y Y W, Q L, Y P S$ and MS performed the experiments and analyzed the data. JKL, LZ and ZPL participated in the research design and manuscript preparation. All authors have read and approved the final manuscript.

\section{ADDITIONAL INFORMATION}

The online version of this article (https://doi.org/10.1038/s41401-019-0340-7) contains supplementary material, which is available to authorized users.

Competing interest: The authors declare no competing interests.

Publisher's note Springer Nature remains neutral with regard to jurisdictional claims in published maps and institutional affiliations.

\section{REFERENCES}

1. Kroeger PT Jr, Drapkin R. Pathogenesis and heterogeneity of ovarian cancer. Curr Opin Obstet Gynecol. 2017;29:26-34.

2. Testa U, Petrucci E, Pasquini L, Castelli G, Pelosi E. Ovarian cancers: genetic abnormalities, tumor heterogeneity and progression, clonal evolution and cancer stem cells. Medicines (Basel). 2018;5:E16.

3. La Vecchia C. Ovarian cancer: epidemiology and risk factors. Eur J Cancer Prev. 2017;26:55-62

4. Festjens N, Vanden Berghe T, Cornelis S, Vandenabeele P. RIP1, a kinase on the crossroads of a cell's decision to live or die. Cell Death Differ. 2007;14:400-10.

5. Meylan E, Burns K, Hofmann K, Blancheteau V, Martinon F, Kelliher M, et al. RIP1 is an essential mediator of Toll-like receptor 3-induced NF-kappa B activation. Nat Immunol. 2004;5:503-7.

6. Zhang DW, Zheng M, Zhao J, Li YY, Huang Z, Li Z, et al. Multiple death pathways in TNF-treated fibroblasts: RIP3- and RIP1-dependent and independent routes. Cell Res. 2011;21:368-71.

7. Kelliher MA, Grimm S, Ishida Y, Kuo F, Stanger BZ, Leder P. The death domain kinase RIP mediates the TNF-induced NF-kappaB signal. Immunity. 1998;8: 297-303.

8. Ting AT, Pimentel-Muinos FX, Seed B. RIP mediates tumor necrosis factor receptor 1 activation of NF-kappaB but not Fas/APO-1-initiated apoptosis. EMBO J. 1996;15:6189-96.

9. Lin $Y$, Devin A, Cook A, Keane MM, Kelliher M, Lipkowitz S, et al. The death domain kinase RIP is essential for TRAIL (Apo2L)-induced activation of IkappaB kinase and c-Jun N-terminal kinase. Mol Cell Biol. 2000;20:6638-45.

10. Kaiser WJ, Offermann MK. Apoptosis induced by the toll-like receptor adaptor TRIF is dependent on its receptor interacting protein homotypic interaction motif. J Immunol. 2005;174:4942-52.

11. Meylan E, Tschopp J. The RIP kinases: crucial integrators of cellular stress. Trends Biochem Sci. 2005;30:151-9.
12. Hur GM, Lewis J, Yang Q, Lin Y, Nakano H, Nedospasov S, et al. The death domain kinase RIP has an essential role in DNA damage-induced NF-kappa B activation. Genes Dev. 2003;17:873-82.

13. Park J, Kanayama A, Yamamoto K, Miyamoto Y. ARD1 binding to RIP1 mediates doxorubicin-induced NF-kappaB activation. Biochem Biophys Res Commun. 2012;422:291-7.

14. Hanahan D, Weinberg RA. Hallmarks of cancer: the next generation. Cell. 2011;144:646-74.

15. Bai L, Xu S, Chen W, Li Z, Wang X, Tang H, et al. Blocking NF-kappaB and Akt by Hsp90 inhibition sensitizes Smac mimetic compound 3-induced extrinsic apoptosis pathway and results in synergistic cancer cell death. Apoptosis. 2011; 16:45-54.

16. Palacios C, Lopez-Perez Al, Lopez-Rivas A. Down-regulation of RIP expression by 17-dimethylaminoethylamino-17-demethoxygeldanamycin promotes TRAILinduced apoptosis in breast tumor cells. Cancer Lett. 2010;287:207-15.

17. Wang X, Ju W, Renouard J, Aden J, Belinsky SA, Lin Y. 17-allylamino-17demethoxygeldanamycin synergistically potentiates tumor necrosis factorinduced lung cancer cell death by blocking the nuclear factor-kappaB pathway. Cancer Res. 2006;66:1089-95.

18. Wang L, Du F, Wang X. TNF-alpha induces two distinct caspase-8 activation pathways. Cell. 2008;133:693-703.

19. Holler N, Zaru R, Micheau O, Thome M, Attinger A, Valitutti S, et al. Fas triggers an alternative, caspase-8-independent cell death pathway using the kinase RIP as effector molecule. Nat Immunol. 2000;1:489-95.

20. Lin Y, Choksi S, Shen HM, Yang QF, Hur GM, Kim YS, et al. Tumor necrosis factorinduced nonapoptotic cell death requires receptor-interacting protein-mediated cellular reactive oxygen species accumulation. J Biol Chem. 2004;279:10822-8.

21. Tenev T, Bianchi K, Darding M, Broemer M, Langlais C, Wallberg F, et al. The Ripoptosome, a signaling platform that assembles in response to genotoxic stress and loss of IAPs. Mol Cell. 2011;43:432-48.

22. O'Donnell MA, Ting AT. RIP1 comes back to life as a cell death regulator in TNFR1 signaling. FEBS J. 2011;278:877-87.

23. Degterev A, Ofengeim D, Yuan J. Targeting RIPK1 for the treatment of human diseases. Proc Natl Acad Sci USA. 2019;116:9714-22.

24. Kondylis V, Pasparakis M. RIP kinases in liver cell death, inflammation and cancer. Trends Mol Med. 2019;25:47-63.

25. Park S, Hatanpaa KJ, Xie Y, Mickey BE, Madden CJ, Raisanen JM, et al. The receptor interacting protein 1 inhibits p53 induction through NF-kappaB activation and confers a worse prognosis in glioblastoma. Cancer Res. 2009;69:2809-16.

26. Wang $\mathrm{Q}$, Chen W, Xu X, Li B, He W, Padilla MT, et al. RIP1 potentiates BPDEinduced transformation in human bronchial epithelial cells through catalasemediated suppression of excessive reactive oxygen species. Carcinogenesis. 2013;34:2119-28.

27. Liu XY, Lai F, Yan XG, Jiang CC, Guo ST, Wang CY, et al. RIP1 kinase is an oncogenic driver in melanoma. Cancer Res. 2015;75:1736-48.

28. Wang Q, Chen W, Bai L, Chen W, Padilla MT, Lin AS, et al. Receptor-interacting protein 1 increases chemoresistance by maintaining inhibitor of apoptosis protein levels and reducing reactive oxygen species through a microRNA-146amediated catalase pathway. J Biol Chem. 2014;289:5654-63.

29. Wang R, Zheng $\mathrm{X}$, Zhang L, Zhou B, Hu H, Li Z, et al. Histone $\mathrm{H} 4$ expression is cooperatively maintained by IKKbeta and Akt1 which attenuates cisplatininduced apoptosis through the DNA-PK/RIP1/IAPs signaling cascade. Sci Rep. 2017;7:41715.

30. Wang $Q$, Shi $S$, He W, Padilla MT, Zhang $L$, Wang $X$, et al. Retaining MKP1 expression and attenuating JNK-mediated apoptosis by RIP1 for cisplatin resistance through miR-940 inhibition. Oncotarget. 2014;5:1304-14.

31. Galluzzi L, Vitale I, Abrams JM, Alnemri ES, Baehrecke EH, Blagosklonny MV, et al. Molecular definitions of cell death subroutines: recommendations of the Nomenclature Committee on Cell Death 2012. Cell Death Differ. 2012; 19:107-20.

32. Galluzzi L, Aaronson SA, Abrams J, Alnemri ES, Andrews DW, Baehrecke EH, et al. Guidelines for the use and interpretation of assays for monitoring cell death in higher eukaryotes. Cell Death Differ. 2009;16:1093-107.

33. He S, Huang S, Shen Z. Biomarkers for the detection of necroptosis. Cell Mol Life Sci. 2016;73:2177-81.

34. Lin Y, Devin A, Rodriguez Y, Liu ZG. Cleavage of the death domain kinase RIP by caspase-8 prompts TNF-induced apoptosis. Genes Dev. 1999;13:2514-26.

35. Lei FX, Jin L, Liu XY, Lai F, Yan XG, Farrelly M, et al. RIP1 protects melanoma cells from apoptosis induced by BRAF/MEK inhibitors. Cell Death Dis. 2018;9:679.

36. Lin $Y$, Yang $Q$, Wang $X$, Liu ZG. The essential role of the death domain kinase receptor-interacting protein in insulin growth factor-l-induced c-Jun $\mathrm{N}$-terminal kinase activation. J Biol Chem. 2006;281:23525-32.

37. Chen W, Wang Q, Bai L, Chen W, Wang X, Tellez CS, et al. RIP1 maintains DNA integrity and cell proliferation by regulating PGC-1alpha-mediated 
mitochondrial oxidative phosphorylation and glycolysis. Cell Death Differ. 2014;21:1061-70.

38. Chauhan AK, Min KJ, Kwon TK. RIP1-dependent reactive oxygen species production executes artesunate-induced cell death in renal carcinoma Caki cells. Mol Cell Biochem. 2017;435:15-24.

39. Darding M, Meier P. IAPs: guardians of RIPK1. Cell Death Differ. 2012;19:58-66.

40. Hitomi J, Christofferson DE, Ng A, Yao J, Degterev A, Xavier RJ, et al. Identification of a molecular signaling network that regulates a cellular necrotic cell death pathway. Cell. 2008;135:1311-23.

41. Zhou W, Yuan J. Necroptosis in health and diseases. Semin Cell Dev Biol. 2014;35:14-23.
42. Bertrand MJ, Vandenabeele P. The Ripoptosome: death decision in the cytosol. Mol Cell. 2011;43:323-5.

43. Galluzzi L, Vanden Berghe T, Vanlangenakker N, Buettner S, Eisenberg T, Vandenabeele $\mathrm{P}$, et al. Programmed necrosis from molecules to health and disease. Int Rev Cell Mol Biol. 2012;289:1-35.

44. He W, Wang Q, Srinivasan B, Xu J, Padilla MT, Li Z, et al. A JNK-mediated autophagy pathway that triggers C-IAP degradation and necroptosis for anticancer chemotherapy. Oncogene. 2014;33:3004-13.

45. Xu Y, Ma HB, Fang YL, Zhang ZR, Shao J, Hong M, et al. Cisplatin-induced necroptosis in TNFalpha dependent and independent pathways. Cell Signal. 2017;31:112-23. 